\title{
Luanda entre fronteiras coloniais e reinvenção dos espaços: diálogo entre Luandino Vieira e António Ole
}

\author{
Alice Girotto \\ Università Ca’ Foscari Venezia
}

\begin{abstract}
Resumo
A proposta de leitura que aqui se apresenta, conduzida com a metodologia da comparação interartística que põe em diálogo o texto literário com o texto artístico, oferece uma reinterpretação do conceito de fronteira, de fundamental importância na literatura angolana dos anos 50 até aos 70 do século XX, a partir de algumas obras de António Ole. A sua produção, pontuada, entre muitíssimos outros temas desenvolvidos pelo artista, por uma reflexão sobre o espaço urbano que desde os anos da independência continua até aos nossos dias, será confrontada com algumas estórias de Luandino Vieira em que "a nossa cidade de Luanda" - como os diferentes narradores amam repetir — desenvolve um papel de primeiro plano.
\end{abstract}

Palavras-chave: comparação interartística; cidade; fronteira; António Ole; Luandino Vieira.

\begin{abstract}
The close-reading proposed, based on the interartistic comparison methodology that makes literary texts dialogue with artistic ones, offers a reinterpretation of the notion of frontier, a very important one for Angolan literature of the Fifties to the Seventies, using some Antonio Ole's works as starting point. His artistic production, punctuated, among many other themes he deals with, by a reflection on urban space that has continued since the period of independence in Angola, is compared here with some short stories by Luandino Vieira in which "a nossa cidade de Luanda" - as their various narrators like to say plays a primary role.
\end{abstract}

Keywords: interartistic comparison; city; frontier; António Ole; Luandino Vieira.

Recebido em: $31 / 03 / 19$

Aprovado em: 24/06/19

No contexto dos estudos sobre literaturas africanas em língua portuguesa o tema da representação da cidade de Luanda é frequente objeto de discussão e aprofundamento. De fato, falar de literatura urbana em relação à capital de Angola pode até resultar pleonástico: a literatura angolana nasce urbana por razões históricas — juntamente com as primeiras publicações jornalísticas em meados do século XIX, que obviamente se desenvolveram nos únicos lugares onde existiam condições de produção, ou seja as cidades — e, por conseguinte, na maioria das 
suas manifestações é urbana por definição. Em particular, a importância estratégica de Luanda logo a partir da sua fundação em 1575 por parte de Paulo Dias de Novais, primeiro como principal porto de partida do tráfico negreiro para o Brasil, depois como sede da administração colonial, capital do Estado independente desde 1975 e destino de um número em constante crescimento de deslocados internos durante os mais de 25 anos de guerra civil, tornou a cidade não um simples pano de fundo ou espaço de ação, mas uma verdadeira protagonista e até metáfora de toda uma nação. Menos estudada é, em contrapartida, a relação que as artes visuais estabeleceram, no seu processo de desenvolvimento, com a cidade: se é verdade, por um lado, que as obras de arte estão menos vinculadas ao ambiente urbano como lugar físico de produção do que o material literário, por outro lado a cidade, pela sua intrínseca constituição como centro nevrálgico de convergência de rotas de comunicação de todo o tipo, é de todas as formas o lugar onde a arte pode ser exposta e vendida e, aliás, encruzilhada do mais amplo espaço de circulação internacional da arte. E, ainda que de forma menos predominante do que nos textos literários, Luanda está presente também nas obras dos artistas plásticos angolanos. ${ }^{1}$

Dadas estas premissas, a proposta de leitura que aqui se apresenta, conduzida com a metodologia da comparação interartística, pretende pôr em diálogo o texto literário com o texto artístico, ${ }^{2}$ assumindo que a análise do segundo pode contribuir para iluminar aspectos que permaneceram na sombra do primeiro e, nessa perspectiva, enquadrá-lo em esquemas interpretativos novos. Em particular, propõe-se uma reinterpretação do conceito de fronteira, de fundamental importância na literatura angolana entre os anos 50 e 70 do século XX, a partir de algumas obras de António Ole, talvez o mais importante artista angolano ainda vivo. A sua produção, pontuada, entre muitíssimos outros temas por ele desenvolvidos, por uma reflexão sobre o espaço urbano que desde os anos da independência continua até aos nossos dias, será confrontada com algumas estórias de Luandino Vieira em que "a nossa cidade de Luanda" como os diferentes narradores amam repetir — desenvolve um papel de primeiro plano.

\footnotetext{
${ }^{1}$ Com efeito, a capital de Angola funciona como "cartão de visita" também em relação ao público internacional. Se tomarmos, por exemplo, o caso da Bienal de Arte de Veneza (cuja importância é dada pelo fato de ter sido a primeira das grandes exposições de arte contemporânea a ser organizada em nível internacional), a cidade foi o centro programático da participação de artistas angolanos por duas vezes: em 2007, no contexto do Pavilhão africano, organizado por Fernando Alvim e Simon Njami por conta da Fundação Sindika Dokolo, com o título emblemático de "Check List Luanda Pop", e em 2013, com a exposição de fotografias de Edson Chagas "Luanda Encyclopaedic City" dentro do pavilhão nacional.

${ }^{2}$ A noção de texto artístico baseia-se nas reflexões teóricas sobre a comparação interartística de dois estudiosos italianos, Alberto Gianquinto e Cesare Segre: o primeiro, a partir das suas pesquisas sobre as linguagens das diferentes expressões artísticas, elaborou uma metodologia de comparação fundamentada na "semântica" e na "sintaxe" a elas inerentes (cf. GIANQUINTO, 1998); o segundo, que foi um importante semiólogo, fala nos seus ensaios de uma "gramática" das imagens composta por um "léxico" e uma "sintaxe", à qual junta também a noção de "narração" (cf. SEGRE, 2003).
} 
Num recente artigo sobre as "vozes literárias de Luanda e Maputo", Margarida Calafate Ribeiro fala de "the dividing line between the colonial city and the shantytown drawn by Luandino Vieira [...], demarcating the European space from the African space" (RIBEIRO, 2016, p. 103), uma linha divisória através da qual se explicava o poder colonial e o seu deliberado "design of inequality" (RIBEIRO, 2016, p. 88). É a "fronteira de asfalto" do homônimo conto de $A$ cidade e a infância, publicado em 1960, forma tangível que inscreve no território as dinâmicas sociais resultantes da criação de "cidades duais" (ROSSA, 2016, p. 112) nas capitais coloniais portuguesas nos anos 50,60 e 70 do século XX, com base no que já acontecera algumas décadas antes em outras partes da África colonial (cf. DAVIS, 2006; FANON, 2011). O conto, que descreve o trágico fim da amizade inter-racial entre Marina (branca) e Ricardo (negro), recorda um tempo em que esta divisão (aparentemente) não existia, um antigo tempo de convivência e concórdia entre "grupos étnicos" diferentes (cf. ERVEDOSA, 1963): "E tu achas que está tudo como então? Como quando brincávamos à barra do lenço ou às escondidas? Quando eu era o teu amigo Ricardo, um pretinho muito limpo e educado, no dizer de tua mãe?" (VIEIRA, 2007, p. 78). Mas a irrupção de um "outro" lado, do mundo dos outros que aparece descrito através de um processo de negação e subtração, é impiedosa:

Virou os olhos para o seu mundo. Do outro lado da rua asfaltada não havia passeio. Nem árvores de flores violeta. A terra era vermelha. Piteiras. Casas de pau-a-pique à sombra de mulembas. As ruas de areia eram sinuosas. Uma ténue nuvem de poeira que o vento levantava, cobria tudo (VIEIRA, 2007, p. 78).

Nas obras que se seguem a $A$ cidade e a infância a fronteira aqui só sugerida com breves pinceladas descritivas delineia-se cada vez mais claramente como linha de demarcação e contraposição entre a Baixa, a parte da cidade habitada pelos colonos, e a cidade de terra vermelha e chapas de zinco da população africana: a Baixa é bonita, ordenada, limpa (“As ruas, as casas, eram bonitas, não eram cubatas de zinco, não, e as estradas, cheias de carros e pessoas, estavam tapadas pelo alcatrão, a areia dos musseques não tinha á'” - VIEIRA, 2003, p. 15), enquanto no musseque domina a sujeira, a confusão, a insalubridade:

O musseque, nessa hora, parecia era uma sanzala no meio da lagoa, as ruas de chuva, as cubatas invadidas por essa água vermelha e suja correndo caminho do alcatrão que leva na Baixa ou ficando, teimosa, em cacimbas de nascer mosquitos e barulhos de rãs (VIEIRA, 2004, p. 16-17).

É a própria ecologia dos ambientes que impede qualquer partilha de destinos no plano social. Como confirmação disso, em Luuanda de 1964 a Baixa é vista de longe, como mundo "outro" para onde se vai (normalmente à procura de trabalho) e de onde se vem, mas que nunca tem a função de cenário para as ações das personagens. Interessante é a maneira como 
a contraposição Baixa-musseque é tratada em "Estória do ladrão e do papagaio", onde é o animal que exemplifica e estereotipa a polaridade entre os dois mundos: mais uma vez, a Baixa representa a ordem, a educação, a pertença à civilização ('Kam'tuta pensava, conhecia papagaio da Baixa era diferente; tinha até um, numa senhora, assobiava hino nacional e fazia toque de corneta do batalhão e tudo" - VIEIRA, 2004, p. 76), enquanto o musseque é todo o contrário ("Jacó, coitado papagaio de musseque, só lhe ensinam as asneiras e nem tem poleiro nem nada" — VIEIRA, 2004, p. 122-123).

No plano visual, o musseque tem sido representado desde as origens do seu percurso artístico por António Ole, personalidade fundamental do panorama artístico angolano e quase um "pai" da geração de artistas plásticos que começaram a realizar as suas obras no terceiro milênio. No contexto de uma poética que faz da reutilização de materiais abandonados o seu eixo principal, a reflexão sobre a fronteira interna da cidade é constante e tem sido reelaborada segundo modalidades diferentes em momentos sucessivos. As fotografias que levam o título de Casas da Xicala (Figs. 1 e 2) são parte de uma série tirada entre 1976 e 1980 nos vários musseques de Luanda (para além do Xicala, foram imortalizados por exemplo o Maianga e o Sambizanga) como documentação do caráter precário e mutável das zonas liminares, mas também das potencialidades de adaptação e reformulação de que são testemunho.

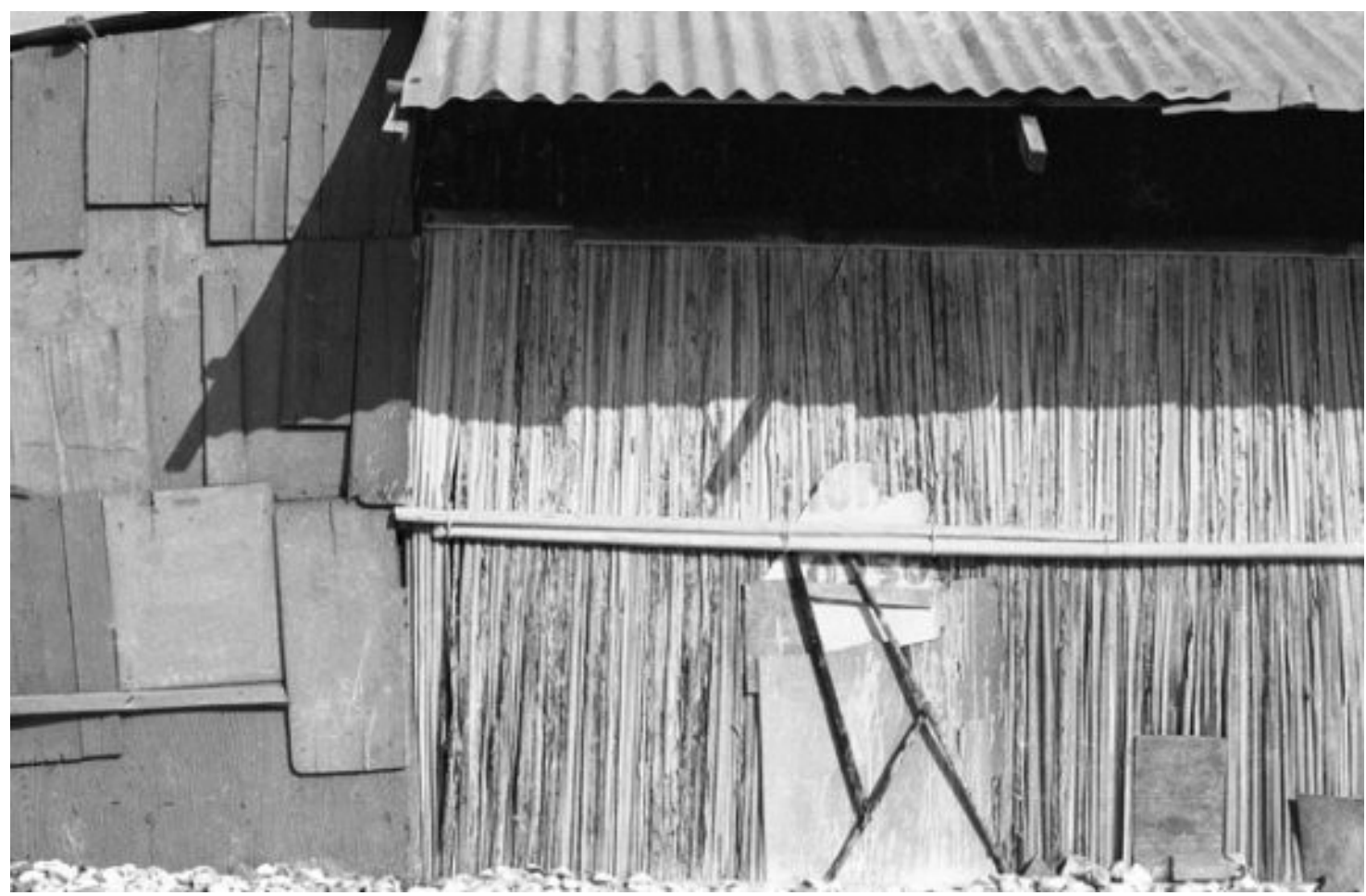

Figura 1. OLE, António. Casas da Xicala. 1976. 1 fotografia. 


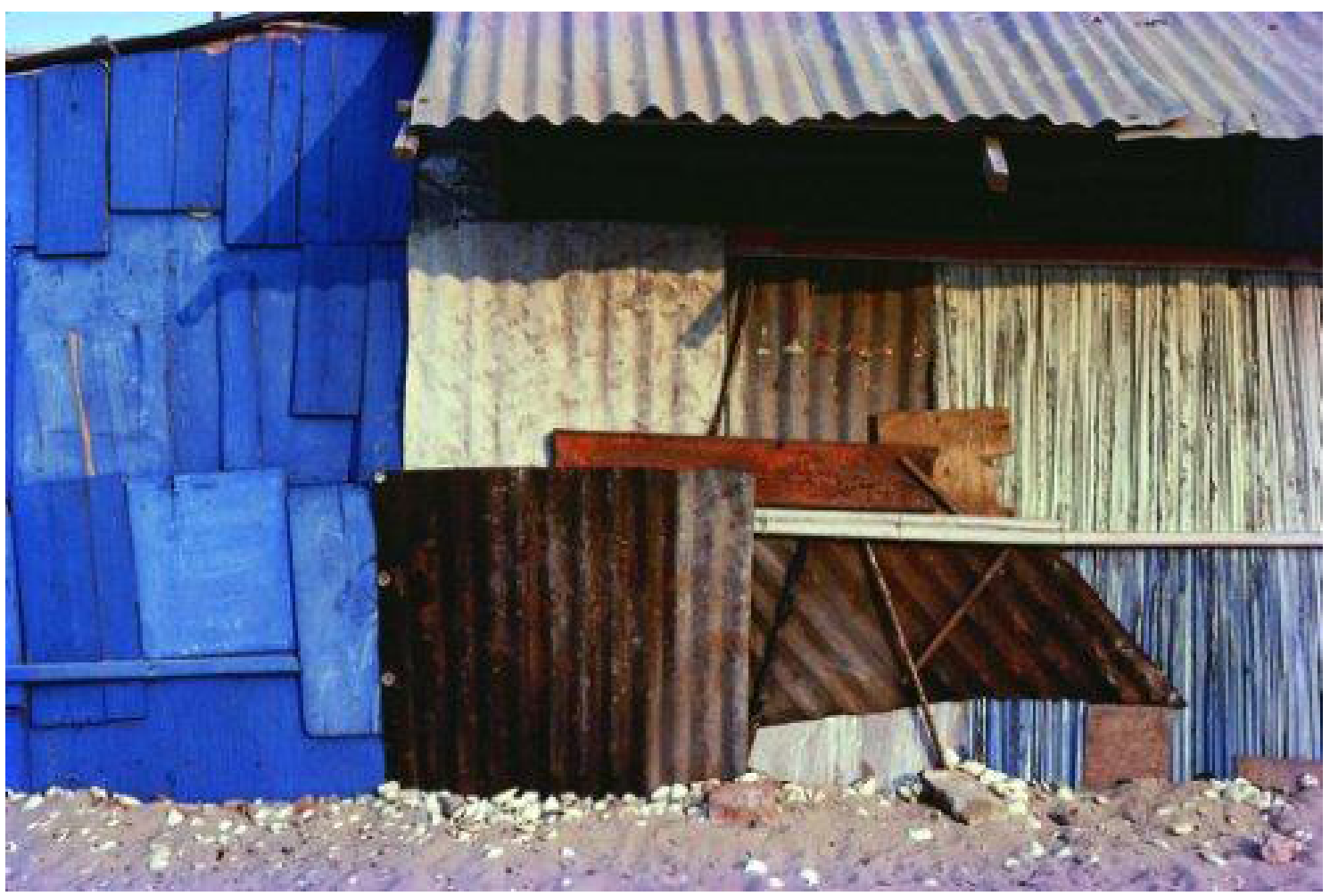

Figura 2. OLE, António. Casas da Xicala. 1976. 1 fotografia.

Em particular, as duas fotografias retratam no mesmo enquadramento e quase nas mesmas condições de luz as duas mesmas habitações, o que se pode verificar observando as dimensões e a disposição das tábuas de madeira da casa de esquerda; na casa à direita, por outro lado, quer o material de composição quer a sua montagem mudaram parcialmente, num período de tempo muito breve (as duas fotografias foram tiradas no mesmo ano de 1976); também a uniformidade cromática da habitação de esquerda em contraposição com o efeito patchwork da de direita parece querer ressaltar a mutabilidade desta, sobretudo se comparada com a relativa uniformidade de tons da mesma na fotografia a preto e branco. É exatamente nestes termos que as imagens são apresentadas no catálogo da exposição Na pele da cidade:

Nas fotografias e instalações de António Ole, encontramos instantâneos dessa arquitectura passageira, que se altera constantemente devido à sua proximidade com a vida humana. A rapidez com que esses espaços vitais modificáveis se alteram e como em apenas uma semana podem ser transformados em novos espaços, sempre o fascinou (SIEGERT, 2009, p. 47).

A tônica posta no material de construção não tem aqui a intenção, como por outro lado acontece nos textos anteriormente mencionados de Luandino Vieira, de delimitar nitidamente uma fronteira que é linha imaginária fundamental para a afirmação da identidade colonial 
(a qual pode realizar-se somente através da separação também física do Outro), mas é o testemunho tangível e concreto das capacidades de resiliência dos habitantes dos musseques, espaços retratados e interpretados pelo artista como verdadeiras "estruturas de sobrevivência" (PEREIRA, 2013, p. 184).

É exatamente nesta perspectiva primeiramente de resiliência, e de resistência e aberta rebelião depois, que pode ser interpretada a evolução do papel destes espaços segregados resultantes da separação desejada e atuada pelo sistema colonial nas cidades: de lugares onde tornar visível mas ao mesmo tempo indesejável a noção de diferença (diferença radicada, entre outros, em fatores raciais e económicos) ${ }^{3}$ e gerar a alteridade conotando-a de forma negativa como obscura, selvagem e, no final das contas, inferior, a incubadoras para o desenvolvimento dos movimentos de libertação nacional. Consequentemente, pode-se afirmar que o "design of inequality" se revelou uma espécie de espada de dois gumes criada pelo colonialismo contra si mesmo, que se expressou não só no plano sociopolítico, como também no literário:

As a result of this social apartheid, the colonial city became a spatial expression of the inequality instated by the colonial order, but also a locus of opportunities. It gave access to work, education, and culture. It provided living conditions of sorts. In effect, this urbanism of inequality transformed the city's peripheries, where people from throughout the colonial territory lived, into the cultural backdrop for a new political awareness and the cradle of a literature of nationhood (RIBEIRO, 2016, p. 92).

De fato, da descrição das diferenças do musseque num registo negativo passou-se quase à exaltação ${ }^{4}$ destas diferenças como elementos caracterizadores e dignos de valorização, fundamentando-se, nomeadamente, na diferenciação linguística como forma para resgatar uma identidade própria. A partir de Luuanda, ${ }^{5}$ o aspeto linguístico é fundamental nas obras de Luandino Vieira: é através do uso peculiar que o autor faz da língua portuguesa que consegue

\footnotetext{
3 A este propósito, veja-se também a descrição que Fanon faz da cidade colonial como de um "mundo compartimentado" em que é a pertença a uma dada raça a determinar a divisão (FANON, 2011, p. 454-455).

${ }^{4}$ Chegando a um ponto tal que, nos anos 60 e 70, em plena guerra de libertação nacional em Angola, se desenvolveu uma verdadeira "literatura do musseque" cujos representantes, para além de Luandino Vieira, são Arnaldo Santos (Quinaxixe, 1965), Jofre Rocha (Estórias de musseque, 1976), Jorge Macedo (Gente de meu bairro, 1977), António Cardoso (Baixa e musseques, 1980) e Boaventura Cardoso.

${ }^{5} \mathrm{Na}$ verdade, já em Vidas novas, cujos contos foram escritos em 1962, havia uma primeira tomada de consciência da centralidade da língua como fator identitário a reivindicar. O conto "Fato completo" é exemplar para o efeito, porque é inteiramente construído à volta do equívoco provocado pela unidade de sentido das duas palavras do título: o seu significado literal, em português europeu, é o de "conjunto de vestuário masculino" e é mesmo assim que as interpretam os polícias protagonistas, os quais, por conseguinte, temem que a chegada à prisão de um "fato completo" trazido por uma mulher ao companheiro preso seja uma maneira para transmitir mensagens por parte de alguma organização política clandestina. Evidentemente, os habitantes de Luanda querem dizer uma coisa completamente diferente: "Essa comida de feijão de azeite-palma com peixe de azeite-palma, a banana e tudo, que toda a gente nos musseques tem só a mania de chamar de fato completo" (VIEIRA, 1976, p. 138).
} 
moldar uma determinada dimensão ideológica da cidade de Luanda como "berço da nação" angolana prestes a nascer. ${ }^{6}$ Não se trata simplesmente da imitação da fala das classes populares luandenses, para transmitir a peculiar "visão do mundo" das mesmas; a ideia política de fundo não é de mera reprodução realística de uma determinada parcela da sociedade para que se revelasse na literatura e, através dela, na política — ou, por melhor dizer, não é só isso. Trata-se sobretudo de uma vontade de intervenção insurrecional, revolucionária, como aliás os próprios eventos históricos contemporâneos tornavam evidente: a apropriação, o controle e a subversão da língua do colonizador enriquecida com elementos próprios da realidade histórico-geográfica e sociocultural local tornavam não só possível uma expressividade individual, autônoma, já não dependente do universo colonial, mas sobretudo tornavam incompreensível, impenetrável (e por isso protegida e potencialmente capaz de inverter a relação de dominação a que fora submetida até então) aquela mesma realidade. A este propósito, é o mesmo autor quem afirma que

[a] questão da linguagem já não é tão inocente assim... Muito embora não pretendesse fazer uma cópia fiel da linguagem utilizada pelas camadas populares luandenses. Tenho que reconhecer - para o caso do Luuanda - que em certa altura eu achei até que teria um significado político: demonstrar que, na própria língua do colonizador, a nossa diferença cultural nos permitia escrever de modo que era difícil, ao próprio colonizador, entender o nosso código linguístico (VIEIRA, 2004, orelha da contracapa).

Todos os comentadores do texto luandino concordam neste ponto: a palavra literária, como aliás acontece em praticamente todos os autores desta geração, torna-se palavra de ordem para a afirmação da identidade nacional (cf., entre muitos outros, FERREIRA, 2009). Na fase seguinte da produção de Luandino, que pode ser identificada com Nós, os do Makulusu e Macandumba, compreende-se ainda melhor uma intenção já presente em Luuanda e nas obras do mesmo período: ${ }^{7}$ a da construção de uma língua literária nova, da linguagem (se não oficial, pelo menos cultural) do futuro. Para além da invenção de palavras, como derivação de formas kimbundu ou deformação das portuguesas, muitas vezes servindo-se de uma "sufixação criativa", ${ }^{8}$ é a subversão da sintaxe o elemento verdadeiramente inovador, o que realmente lança as bases da nova linguagem, expressão de uma angolanidade exuberante e fantasiosa: "Poeta de musseque sempre não é o matemático - não conhece estatuto das palavras, tudo é a livre anarquia: ritmo é quem que manda, verso obedece só" (VIEIRA, 1978, p. 74).

\footnotetext{
${ }^{6}$ Rita Chaves apreende esta dimensão no seu sentido pleno quando afirma que "dos becos de Luuanda projetava-se uma perspetiva de nação" (CHAVES, 2010, p. 13).

${ }^{7}$ Como afirmado pelo próprio autor numa entrevista concedida a Pires Laranjeira, em 1994, para a Universidade Aberta (cf. VIEIRA, 2004, orelha da contracapa).

${ }^{8} \mathrm{Um}$ exemplo entre os muitíssimos que se poderiam dar, analisando em detalhe individualmente os textos do autor, é a denotação de um homem como "habitante de musseque", pela qual podem ser encontrados na sua obra pelo menos três adjetivos diferentes: "mussequista", "mussequeiro" e "mussequense".
} 
Eis então que se impõe, neste período logo após a independência, uma atenção nova à criatividade dos espaços de fronteira, que se torna ao mesmo tempo possível e manifesta graças à sua precariedade. A convivência de precariedade e vitalidade é um elemento retomado por António Ole na obra significativamente intitulada Na margem da zona limite (Fig. 3), instalação concebida na capital angolana em 1994 em que a justaposição de resíduos encontrados nas ruas dos musseques constrói uma parede que sugere, sim, uma fronteira intransponível, mas ao mesmo tempo a capacidade de imaginar caminhos de saída para além das barreiras impostas, uma vez que não faltam portas, janelas e brechas. Em contrapartida, quase vinte anos depois da independência nacional, estas zonas da cidade, que já não representavam a dicotomia inerente à ordem colonial, continuavam a simbolizar uma diferença tangível entre quem tirara proveito das contingências históricas e conseguira libertar-se da condição de marginalidade, inclusivamente saindo deste espaço, e quem, por outro lado, pelos eventos da história fora dominado e canalizara as suas esperanças de sobrevivência nestes lugares periféricos e cada vez mais sobrelotados. ${ }^{9}$

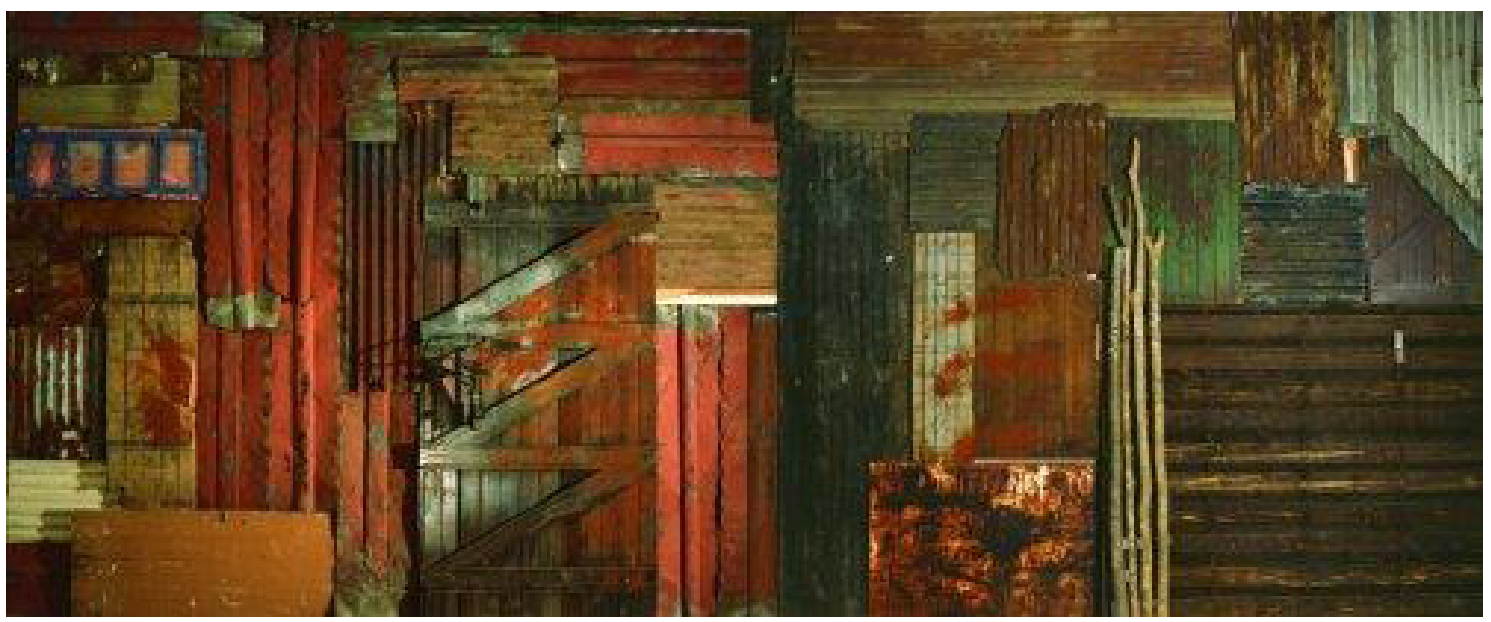

Figura 3. OLE, António. Na margem da zona limite. 1994. 1 instalação.

Não é por acaso, porém, que a atenção de Ole não se foca, tanto aqui como nas obras anteriormente analisadas e nas que se seguem, na área-musseque, mas sim na linha-fronteira, já que sujeito de todas estas obras (fotografias, instalações, colagens) são umas paredes. O acento, portanto, não é posto pelo artista na contraposição entre um "aqui" e um “ali", entre um "nós" e um "eles", entre pobres e ricos, mas no encontro possível entre estas duas alteridades e na

\footnotetext{
${ }^{9}$ Cf.: "Angola was forcibly urbanized by more than a quarter-century of civil war (1975 to 2002) — spurred on by the machinations of Pretoria and the White House - which displaced 30 percent of the population. Many refugees never returned to their former homes in the ruined and dangerous countryside, but squatted instead in the bleak musseques (shantytowns) that surround Luanda, Lobito, Cabinda, and other cities. As a result, Angola, only 14 percent urban in 1970, is now a majority urban nation" (DAVIS, 2006, p. 48-49).
} 
mudança cultural que as zonas de contacto podem favorecer devido à sua permeabilidade e aos contínuos movimentos e intercâmbios que aí acontecem:

É patente que uma conceptualização da metáfora da fronteira nos termos que tenho vindo a sintetizar a reinterpreta num sentido que rompe inapelavelmente com uma das conotações que lhe estão mais intimamente associadas: a noção de que a "linha" de fronteira define rigidamente uma binaridade entre um dentro e um fora, o totalmente familiar e o inteiramente estranho, não consentindo, assim, qualquer modo de mediação ou de articulação. No inverso, teríamos a ideia de que a fronteira é um medium de comunicação, o espaço habitável em que o eu e o outro encontram uma possibilidade de partilha e, assim, a possibilidade de dar origem a novas configurações de identidade (RIBEIRO, 2002, p. 483).

Exemplar, neste sentido, é outro conto de Luandino Vieira, cujo título por si só reflete esta noção de fronteira como zona de contacto onde ocorre o encontro das diferenças: "Cangundos, verdianos, santomistas, nossa gente" narra os intricados acontecimentos relativos a um bilhete de lotaria falsificado que chegou às mãos de um polícia, o qual leva perante as autoridades os atores relacionados com as diferentes fases da estória. O que interessa mais deste conto, para além dos diferentes artifícios e detalhes das vidas quotidianas das personagens que são testemunho da criatividade viva de quem, posto em cheque pelas dificuldades da vida, encontra uma maneira de reagir e adaptar o seu percurso consequentemente, são as personagens e a sua caracterização. O "cangundo" do título é precisamente um branco de baixo estatuto social, que vive no musseque Sambizanga e que deste assimilou as características socioambientais ao ponto de ser lá conhecido já não pelo nome de batismo, Joaquim Ferreira Júnior, mas pelo de Evu com que o alcunham os outros habitantes africanos; os seus próprios costumes e maneira de falar refletem uma transformação em ato que já o afastou das origens portuguesas: "o Ferreira lhe agarraram na pronúncia mussequenta dele, um cangundo daqueles nem dois anos se tinha de Luanda, ainda falava bê no vê da terra dele, e já pretoguesava" (VIEIRA, 1978, p. 59). "Verdiano" e "santomista" são as outras duas personagens, os dois mestiços imigrados a Luanda de Cabo Verde e São Tomé e Príncipe, que se apaixonam por duas mulheres cuja pertença étnica é, por várias razões, uma barreira à prossecução feliz de uma relação. O primeiro, Roberto Furtado, é submetido à chantagem do tio de Fátima da Conceição que, em virtude do suposto respeito pelas leis da tradição bantu, lhe extorque uma quantia cada vez maior de favores e dinheiro; o segundo, Alceu Antonino, encontra a oposição da irmã que assiste à progressiva redução das poupanças dos dois por causa dos contínuos presentes de Alceu à menina Sara, "uma brancota redondeca $[\ldots]$ cangunda branca-de-segunda sem as dúvidas, filha do país, cadavez sulana de genealógicos deportados políticos roídos de febres e matacanhas em presídios de Benguela e Caconda..." (VIEIRA, 1978, p. 85). A pertença de todas as personagens a um mesmo espaço misto e de troca inter-racial e intercultural é o elemento mais importante que emerge do conto 
e isso é confirmado também pelo papel dos polícias, obviamente brancos, que aqui todavia não encarnam a alteridade contraposta e com a qual é impossível comunicar-se, mas são parte ativa da história, como o agente Justiniano, "branco do país, e homem de quimbandeira avençada para casos de muita confusão, falavam as invejas" (VIEIRA, 1978, p. 58).

A evolução sucessiva deste tipo de reflexão sobre a fronteira na obra de António Ole é representada pela série Township wall (Fig. 4), em que as paredes têm a função de textos visuais e arquivos memoriais dos habitantes dos diferentes lugares onde foram erguidas (em Chicago, Berlim, na Bienal de Veneza, em Lisboa, Düsseldorf e Washington): o material de que são compostas, de fato, é sempre encontrado no local das exposições, ampliando desta maneira a perspectiva de aplicação da metáfora da fronteira à cidade como tal e não somente a um universo geográfico específico.

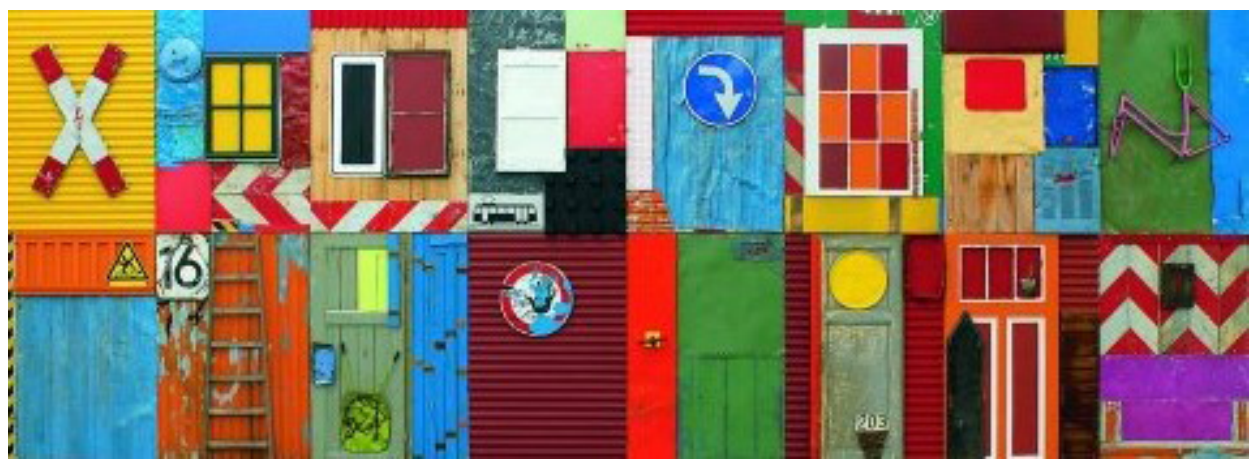

Figura 4. OLE, António. Township wall. 2001. 1 instalação.

Permanecendo, porém, em Luanda, a colagem de 2014 O mural de Maculusso (Fig. 5), cuja explosão cromática é uma autocitação das diferentes fases de produção do autor - desde as pinturas dos anos 1970 num estilo entre a pop art e o surrealismo até às fotografias a preto e branco na preparação de documentários realizados para a televisão de Estado - , prossegue a reflexão sobre a memória, relembrando a estratificação e a mudança contínua da vida urbana, comparada com os muros onde os cartazes publicitários são colados um sobre o outro e nos quais o tempo, riscando-os, rasgando-os e deixando reemergir os mais antigos, age como um artista inconsciente e anacrônico. A escolha, mais uma vez, de não pôr no centro das suas reflexões sobre a cidade a figura humana ${ }^{10}$ mas sim os vestígios da passagem do homem pelo espaço físico urbano parece indicar uma pista de leitura que prefere ter em conta os resultados das ações concretas em lugar das configurações ideológicas apriorísticas que determinam divisões baseadas em preconceitos - resultados em relação aos quais o cromatismo vivo e exuberante destas obras sugere um otimismo de fundo do artista.

\footnotetext{
${ }^{10}$ Isso não significa que a figura humana não interesse ao artista, que aliás precisamente dos habitantes dos musseques tirou uma série de retratos a preto e branco entre 1973 e 1979.
} 


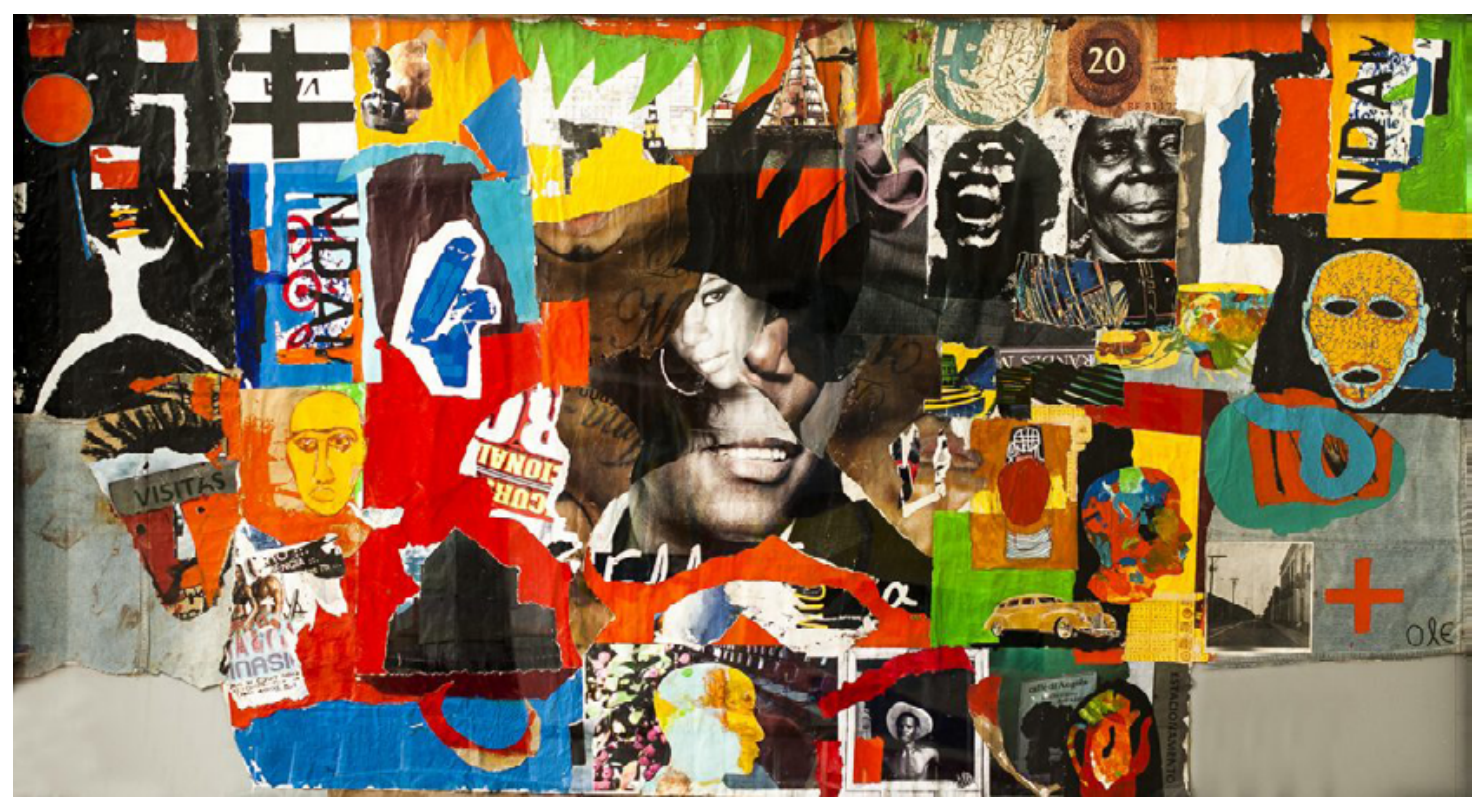

Figura 5. OLE, António. O mural de Maculusso. 2014. Técnica mista e colagem sobre plástico.

É possível, então, afirmar que a leitura que António Ole faz das relações de força existentes entre as diferentes componentes da sociedade urbana privilegia o aspecto comunicativo, em que a possibilidade de partilha e contaminação do espaço habitável dá origem a novas configurações de identidade. A aplicação desta chave de interpretação às obras literárias que põem em cena a cidade de Luanda, como neste artigo foi feito com alguns contos de Luandino Vieira, permite deslocar o foco da atenção crítica da contraposição polarizadora com que tradicionalmente é identificado o conceito de fronteira para os elementos que são testemunho da concreta miscigenação e recriação que ocorre nos espaços fronteiriços. Desta maneira, a percepção conservadora e excludente que se tem deles transforma-se no reconhecimento do seu valor positivo e emancipador, ultrapassando a binaridade típica do contexto colonial e dando lugar a uma leitura mais multifacetada da realidade urbana contemporânea.

\section{Referências}

CHAVES, Rita. A propósito da narrativa contemporânea em Angola: notas sobre a noção de espaço em Luandino Vieira e Ruy Duarte de Carvalho. In: SECCO, Carmen Tindó et al. África: escritas literárias. Rio de Janeiro: Editora da UFRJ; Luanda: União dos Escritores Angolanos. 2010. p. 13-21. v. 1.

DAVIS, Mike. Planet of slums. London; New York: Verso, 2006.

ERVEDOSA, Carlos. A literatura angolana. Lisboa: Casa dos Estudantes do Império, 1963.

FANON, Frantz. Oeuvres. Paris: La découverte, 2011.

FERREIRA, Carla. A conquista da cidade na narrativa de Luandino Vieira: a cidade e a infância e vidas novas. Lisboa: Vega, 2009. 
GIANQUINTO, Alberto. Interazioni semantiche e sintattiche: intermedialità e paragone delle arti, Testo e senso, $1^{\text {a }}$ série, Roma, p. 13-26, 1998.

PEREIRA, Teresa Matos. A cidade visível e a cidade tangível: a paisagem urbana como palimpsesto na obra de António Ole, Revista Estúdio, Artistas sobre Outras Obras, 4a série, Lisboa, v. 8, p. 181-187, 2013.

RIBEIRO, António Sousa. A retórica dos limites: notas sobre o conceito de fronteira $I n$ : SANTOS, Boaventura de Sousa. A globalização e as ciências sociais. São Paulo: Cortez, 2002. p. 475-502.

RIBEIRO, Margarida Calafate. Literary voices of Luanda and Maputo: a struggle for the city, Journal of lusophone studies, 1'a série, Stanford, CA, v. 1, p. 88-106, 2016.

ROSSA, Walter. Luanda and Maputo: accounts of the two capitals in urban heritage discourse, Journal of lusophone studies, 1ª série, Stanford, CA, v. 1, p. 107-116, 2016.

SEGRE, Cesare. La pelle di san Bartolomeo: discorso e tempo dell'arte. Torino: Einaudi, 2003.

SIEGERT, Nadine. A beleza da arquitectura elusiva. In: PIGNATELLI, João (Org.). Na pele da cidade / In the skin of the city. Catálogo da exposição (Luanda, $11 \mathrm{dez} .2009-29$ jan. 2010). Luanda: Instituto Camões. Centro cultural português, 2009. p. 44-50.

VIEIRA, Luandino. Vidas novas. Lisboa: Edições 70, 1976. . Macandumba. Lisboa: Edições 70, 1978. . Nosso musseque. Lisboa: Caminho, 2003. . Luuanda. Lisboa: Caminho; Luanda: Nzila, 2004. . A cidade e a infância: contos. Lisboa: Caminho, 2007.

\section{Minicurrículo}

Alice Girotto é doutora em Línguas, Culturas e Sociedades Modernas pela Universidade Ca' Foscari de Veneza, onde defendeu a tese Formas de representação do poder em Angola: uma viagem da literatura às artes visuais (e volta). Participou como relatora de vários congressos internacionais, entre os quais o XII Congresso da Associação Internacional dos Lusitanistas (Macau, 2017), o I Congresso de Jovens Hispanistas e Lusitanistas (Paris, Sorbonne Université, 2018) e o XLV Congresso da African Literature Association (Columbus, Ohio, 2019). 